\title{
Analysis on the Current Situation of AIDS Knowledge Among College Students and the Effect of Intervention
}

\author{
Xue Zeng \\ Primary Education Major \\ Chengdu University \\ Chengdu, China
}

\author{
Yunfeng Huang \\ Chengdu University \\ Chengdu, China
}

Siyuan Xia

Primary Education Major

Chengdu University

Chengdu, China

\author{
Chenli Shen \\ Primary Education Major \\ Chengdu University \\ Chengdu, China \\ Weiqi $\mathrm{He}$ \\ Primary Education Major \\ Chengdu University \\ Chengdu, China
}

\begin{abstract}
In order to understand the knowledge of AIDS among college students and the basic situation of life skills of AIDS prevention, behavioral intervention was carried out to understand the effect of intervention, so as to provide the basis for health education in colleges and universities. By using the method of random sampling, the college students in a university in Chengdu were selected as the objects of intervention, and 562 valid questionnaires were sent out, 562 valid questionnaires in the base line survey and 562 valid questionnaires in the final survey. AIDS health education was carried out by means of volunteer propaganda, peer education and special lectures on AIDS prevention. The results show that the awareness rate of AIDS transmission, cognition and life skills among college students has been improved. The awareness rate of the transmission route of the disease was higher, but the awareness rate of the non-transmission route of AIDS was low, and the awareness rate of AIDS testing was the highest, which were $41.81 \%$ and $96.44 \%$ respectively before and after intervention. On the whole, college students' understanding of AIDS knowledge and AIDS prevention life skills is low, and the knowledge structure is more one-sided. Through the intervention of AIDS knowledge and health education, the awareness rate of AIDS among college students can be significantly improved.
\end{abstract}

Keywords-college students; AIDS; intervention

\section{INTRODUCTION}

As a global infectious disease, AIDS (aids) is a disease caused by human immunodeficiency virus (HIV) infection, and there is still no effective preventive vaccine and therapeutic drug [1]. According to the UNAIDS (unaids) report, one-third of all people living with HIV in the world are young people aged 15-24 [2]. Therefore, it is of great significance for college students to carry out AIDS knowledge health education intervention, which not only helps to improve college students' awareness of AIDSrelated knowledge and their ability to prevent AIDS, but also helps colleges to find the most effective intervention methods. The survey was conducted in a university in Chengdu. The volunteers' propaganda, peer education, and anti-Ai special lectures were used to conduct knowledge and behavior interventions for college students, to improve college students' awareness of AIDS, and to explore the best intervention methods.

\section{OBJECT AND METHOD}

The subject of a university in Chengdu is a freshman to senior.

A random questionnaire was used to conduct a random questionnaire survey of college students in a university in Chengdu. In the early stage of the study, a baseline survey was conducted on the respondents to understand the AIDS transmission pathways, cognition, testing, and life skills of college students. In the medium term, volunteers, peer education, and AIDS prevention lectures were used to conduct AIDS knowledge health among respondents. The education intervention and the questionnaire were used to test the effect of the intervention, and the questionnaires 
issued in the middle of the collection were collected and analyzed and analyzed.

In the early stage of research, 600 questionnaires were distributed, 562 valid questionnaires were returned, the effective rate was 93.67\%, 600 questionnaires were distributed later in the study, and 562 valid questionnaires were collected, with an effective rate of $93.67 \%$.The questionnaire consists of three parts: basic information, basic knowledge and life skills. The questionnaire is not registered and is filled in on the spot.

In the form of scoring, the scores of the answers to each question are divided into two categories, one is completely correct for 4 points, the roughly correct is 3 points, the more correct is 2 points, and the basic correct is 1 point. The error is 0 ; one is correct for 4 points, the uncertainty is 2 points, and the error is 0 points. The total score of the questionnaire was divided into three score segments, 62-74 points for complete understanding, 44.4-62 points for basic understanding, and 44.4 points for less understanding.

\section{RESULTS}

\section{A. Basic Situation}

There were 562 college students participating in the survey and intervention, including 432 female students, accounting for $76.87 \%, 130$ male students, accounting for $23.13 \%$; 519 freshmen, accounting for $92.35 \%$, and sophomores 41 , accounting for $41.7 .3 \%, 0$ juniors, $0 \%, 2$ seniors, $0.35 \%$; 250 primary education, $44.48 \%, 272$ preschool education, $48.4 \%$, special education 5 people, accounting for $0.89 \%, 35$ applied psychology, accounting for $6.23 \%$.This shows that there are more girls than boys in this survey, mainly freshmen, mainly in the field of teachertraining.

\section{B. Basic Knowledge}

1) Knowing the route of AIDS transmission: The total awareness rate of the three main transmission routes of AIDS (sexual contact transmission, mother-to-child transmission, blood transmission) reached $66.37 \%$, which was $25.27 \%$ higher than that before intervention $(41.1 \%)$, and the mosquito-bite was not known as the nontransmission route. It increased from $50.18 \%$ to $76.51 \%$, indicating that the intervention was effective (See the "Table I" below).

TABLE I. KNOWING THE ROUTE OF AIDS TRANSMISSION

\begin{tabular}{|l|l|l|l|l|}
\hline \multirow{2}{*}{ Way } & \multicolumn{3}{|c|}{ Knowing the route of AIDS transmission } \\
\cline { 2 - 5 } & \multicolumn{2}{|c|}{ Before intervention } & \multicolumn{2}{c|}{ After intervention } \\
\hline $\begin{array}{l}\text { Qumber of } \\
\text { people }\end{array}$ & Awareness rate & $\begin{array}{l}\text { Number of } \\
\text { geople }\end{array}$ & Awareness rate \\
\hline $\begin{array}{l}\text { Question6: When you have sex with the blood with HIV } \\
\text { a homosexual, you don't have to use } \\
\text { a condom. }\end{array}$ & 526 & $93.59 \%$ & 537 & $95.55 \%$ \\
\hline $\begin{array}{l}\text { Question7: Is it possible for a child } \\
\text { born to a woman infected with HIV } \\
\text { to get AIDS? }\end{array}$ & 517 & $85.77 \%$ & 509 & $90.57 \%$ \\
\hline $\begin{array}{l}\text { Question10: Will mosquito bites send } \\
\text { AIDS? }\end{array}$ & 282 & $91.99 \%$ & 515 & $91.64 \%$ \\
\hline
\end{tabular}

2) Knowledge of HIV testing: As can be seen from "Table II", the awareness rate of HIV testing after intervention reached $96.44 \%$, an increase of $4.63 \%$, which indicated that the intervention was effective.

TABLE II. KNOWLEDGE OF HIV TESTING

\begin{tabular}{|l|c|c|c|c|}
\hline \multirow{2}{*}{} & \multicolumn{3}{|c|}{ Knowledge of HIV testing } \\
\cline { 2 - 5 } Awareness of HIV testing & \multicolumn{2}{|c|}{ Before intervention } & \multicolumn{2}{|c|}{ After intervention } \\
\hline $\begin{array}{l}\text { Question21: issue of high-risk sexual behavior, AIDS } \\
\text { testing should be done as soon as possible }\end{array}$ & 516 & $\begin{array}{l}\text { Number } \\
\text { of people }\end{array}$ & $\begin{array}{l}\text { Awareness } \\
\text { rate }\end{array}$ \\
\hline
\end{tabular}

3) AIDS awareness: The total awareness rate of AIDS awareness among respondents was $26.33 \%$ before intervention to $75.44 \%$ after intervention. Among them, "for college students, the probability of contracting AIDS is greater than the probability of having cancer", the awareness rate increased by nearly $26 \%$ from $46.62 \%$ to $72.06 \%$, which indicated that the respondents were more alert to HIV after intervention. (See "Table III"). 
TABLE III. AIDS AWARENESS

\begin{tabular}{|l|c|c|c|c|}
\hline \multirow{2}{*}{ Cognitive situation } & \multicolumn{4}{|c|}{ AIDS awareness } \\
\cline { 2 - 5 } & \multicolumn{2}{|c|}{ Before intervention } & \multicolumn{2}{|c|}{ After intervention } \\
\hline $\begin{array}{l}\text { Question 11: For college students, } \\
\text { people of }\end{array}$ & 262 & Awareness rate & $\begin{array}{l}\text { Number of } \\
\text { people }\end{array}$ & Awareness rate \\
$\begin{array}{l}\text { fereater of contracting AIDS is } \\
\text { suffering from cancer. }\end{array}$ & & & $46.62 \%$ & $72.06 \%$ \\
\hline $\begin{array}{l}\text { Question13: Everyone has the } \\
\text { possibility of contracting AIDS. }\end{array}$ & 432 & $76.87 \%$ & 483 & $85.94 \%$ \\
\hline
\end{tabular}

\section{Life Skills}

1) Knowing the situation and attitude of the correct use of condoms: After calculation, the total awareness rate of college students using condoms correctly increased to
$85.59 \%$ before intervention $(75.62 \%)$, and the awareness rate of homosexual relationship and heterosexual relationship increased from $85.77 \%$ and $78.47 \%$ to $95.02 \%$ and $88.61 \%$, respectively (see the "Table IV" below).

TABLE IV. KNOWING The SituAtion AND ATtitude of THE CORRECT USE OF CONDOMS

\begin{tabular}{|l|l|l|l|l|}
\hline \multirow{2}{*}{} & \multicolumn{2}{|c|}{ Before intervention } & \multicolumn{2}{c|}{ After intervention } \\
\cline { 2 - 5 } & $\begin{array}{l}\text { Number of } \\
\text { people }\end{array}$ & Awareness rate & $\begin{array}{l}\text { Number of } \\
\text { people }\end{array}$ & Awareness rate \\
\hline $\begin{array}{l}\text { Question6: When you have sex } \\
\text { with a homosexual, you don't have } \\
\text { to use a condom. }\end{array}$ & 482 & $85.77 \%$ & 534 & $95.02 \%$ \\
\hline $\begin{array}{l}\text { Question 15: Can the correct use } \\
\text { of condoms reduce the spread of } \\
\text { AIDS? }\end{array}$ & 512 & $91.1 \%$ & 536 & $95.37 \%$ \\
\hline $\begin{array}{l}\text { Question17: If the other person } \\
\text { does not want to use a condom } \\
\text { when he or she has sex with a } \\
\text { boyfriend/girlfriend, i will reject } \\
\text { the request from the other party. }\end{array}$ & 441 & $78.47 \%$ & 498 & $88.61 \%$ \\
\hline
\end{tabular}

2) Cognition of AIDS patients: After the intervention, "Is a person infected with AIDS able to see it from the outside?" and "Is HIV infection with people living with HIV or AIDS?" The awareness rate has not changed significantly, indicating that the respondents are AIDS patients. There are still some misunderstandings in cognition, but the total awareness rate after intervention $(83.45 \%)$ is higher than before (See the "Table V" below).

TABLE V. COGNITION OF AIDS PATIENTS

\begin{tabular}{|l|l|l|l|l|}
\hline \multirow{2}{*}{} & \multicolumn{3}{|c|}{ Cognition of AIDS patients } \\
\cline { 2 - 5 } & \multicolumn{3}{|c|}{ Before intervention } & \multicolumn{2}{c|}{ After intervention } \\
\hline Cognition of AIDS patients & $\begin{array}{l}\text { Number of } \\
\text { people }\end{array}$ & Awareness rate & Number of people & Awareness rate \\
\hline $\begin{array}{l}\text { Question8: Can a person infected with } \\
\text { AIDS be seen from the outside? }\end{array}$ & 446 & $79.36 \%$ & 504 & $89.68 \%$ \\
\hline $\begin{array}{l}\text { Question9: Is it AIDS if you eat with } \\
\text { HIV-infected patients or patients? }\end{array}$ & 460 & $81.85 \%$ & 502 & $89.32 \%$ \\
\hline
\end{tabular}

3) Knowing the behavior of increasing the chance of HIV infection:It was calculated that the total awareness rate of increasing the chance of HIV infection after intervention increased from $44.84 \%$ to $60.68 \%$, an increase of nearly $16 \%$. The awareness rate of the good friend who borrowed the razor/eyebrow knives to disinfect after use was $29.54 \%$ to $69.93 \%$, an increase of $40.39 \%$, which indicates that the intervention effect is good (See the "Table VI" below). 
TABLE VI. KNOWING THE BEHAVIOR OF INCREASING THE CHANCE OF HIV INFECTION

\begin{tabular}{|l|l|l|l|}
\hline & \multicolumn{2}{|c|}{ Knowing the behavior of increasing the chance of HIV infection } \\
\cline { 2 - 5 } & \multicolumn{1}{|c|}{ Before intervention } & After intervention \\
\hline $\begin{array}{l}\text { Awareness of behaviors that increase the } \\
\text { chance of HIV infection }\end{array}$ & Number of people & Awareness rate & Number of people \\
\hline $\begin{array}{l}\text { Question 4: If a good friend borrows my } \\
\text { razor/eyebrow knives, I will use it after } \\
\text { disinfection. }\end{array}$ & 166 & $29.54 \%$ & 393 \\
\hline $\begin{array}{l}\text { Question 12: Problem STD is more } \\
\text { susceptible to HIV than people without } \\
\text { Sexually Transmitted Diseases }\end{array}$ & 393 & $69.93 \%$ & 475 \\
\hline $\begin{array}{l}\text { Question14: The use of new synthetic drugs } \\
\text { (ecstasy, k powder, etc.) will increase the } \\
\text { chance of contracting AIDS. }\end{array}$ & 437 & $77.76 \%$ & 493 \\
\hline $\begin{array}{l}\text { Question19: Which of the following sex- } \\
\text { related behaviors is high-risk behavior of } \\
\text { HIV infection? }\end{array}$ & 332 & $59.52 \%$ & 852 \\
\hline $\begin{array}{l}\text { Question20: Male homosexual sex is a high- } \\
\text { risk group infected with AIDS. }\end{array}$ & 416 & $74.02 \%$ & $80.43 \%$ \\
\hline
\end{tabular}

\section{CONCLUSION}

In recent years, due to the strong attention of the state and society to AIDS, and the adolescents are high-risk groups of AIDS, colleges and universities have paid more and more attention to the health education of AIDS among college students, improving their self-protection awareness and reducing the occurrence of high-risk behaviors.

\section{A. Through Various Forms of Behavioral Intervention, the Awareness Rate of College Students About AIDS Transmission Has Increased Significantly}

According to a number of studies, adolescents are a highrisk group infected with AIDS. The most direct way to prevent HIV infection is to avoid all kinds of ways to spread AIDS. Therefore, it is an inevitable educational process for college students to master the transmission of AIDS. Although adolescents receive more cultural education and have a certain amount of knowledge, according to the results of the baseline survey, there are still some loopholes in the transmission of AIDS among college students. The total awareness rate is $41.1 \%$. After the behavior intervention, the understanding of college students in this aspect has been significantly improved, and the total awareness rate after intervention is $66.37 \%$.Compared with people of other ages, college students have higher efficiency in receiving knowledge, but their knowledge of AIDS transmission mainly comes from their own independent exploration of AIDS and major news, plus school health care for AIDS. There is less education, so college students have a relatively one-sided understanding of the AIDS transmission route.

\section{B. College Students Have a New Understanding of the High-risk Behaviors of AIDS}

In daily life, there are many behaviors that can spread AIDS. At the same time, there are many things that people mistakenly believe can spread AIDS. College students are investigated for some behaviors. At the baseline survey, people are able to infect themselves. The overall awareness rate of AIDS behaviors is $44.84 \%$. Most people have misunderstandings about the behavior of increasing AIDS.
After health education, the total awareness rate of such problems is $60.68 \%$, compared with before intervention. The increase of $15.84 \%$, in addition to the school needs to provide students with the necessary knowledge education, the state and society should also take corresponding measures, there are still many sexual and drug transactions in many parts of the society, which is the high risk of AIDS Behavior, the society is not yet fully effective in resisting such dangerous behaviors, the state should be strongly resisted.

\section{Taking a Variety of Forms of Intervention Helps College Students to Fully Understand AIDS}

According to the survey results of the baseline survey, AIDS health education has been targeted. The intervention methods include: issuing anti-AIDS information, 12.1 antiAIDS publicity, peer education, anti-AIDS education lectures, and anti-AIDS theme class meetings.

For the distribution of anti-AIDS information, after the volunteers sent the information manual of the anti-AIDS to the students, only some of the students can carefully watch and remember the relevant knowledge, and the knowledge is less efficient.

For peer education, there is a group of peers who talk on an equal basis. It usually adopts an informal collection form, which is a discussion about AIDS topics under the guidance of the moderator. In this process, the transmission of information and knowledge is achieved. The effectiveness of peer education lies in its social participation. It integrates young people into discussions and activities, and it is more conducive to learning than simply acquiring information [3].Therefore, peer education is a very appropriate way to convey information about AIDS. It allows young people to participate in activities that may be in the form of games, contests or role plays. All of this helps people see things new, not being told what to think or do. However, in the process of peer education, other students in the group did not ask very meaningful questions to answer, resulting in a long silence. Peer educators did not really understand their tasks, and did not pay attention to the main issues. Start with, but 
mechanically recite some of the concepts that are correct but not practical [4].

In the process of anti-AIDS lectures and anti-Aiban meetings, this method covers a large number of people, and can organize hundreds of people at a time, but the students' interest is not high, there are many whispers in the bottom, self-playing mobile phones Phenomenon, and this traditional teaching method is nothing new, the students' enthusiasm is not high, resulting in poor performance of the activities, there are still a small number of students cannot master the relevant knowledge of AIDS.

\section{All Aspects Should Strengthen AIDS Education for College Students}

AIDS is not just a matter for one person, but also for families, schools, and society. First of all, for students themselves, they must actively understand the relevant knowledge of AIDS, participate in various educational activities, and go to the high-risk areas where AIDS is at risk. Distinguish between right and wrong. For the family where the student is located, the parents should educate the students about the correct and appropriate sexual knowledge. At the same time, parents should strengthen their awareness of AIDS so that they can give appropriate education to the students. In terms of schools, college students mainly use the Internet to obtain knowledge about AIDS prevention and control. Schools should take corresponding measures against relevant departments to strengthen the construction of student housing networks and health education. [5] Schools should improve the school's health education mechanism, increase the health education of students, stimulate students' enthusiasm for learning health knowledge, and increase the accumulation of AIDS knowledge among students. Schools can hold AIDS knowledge contests regularly or set up student-oriented AIDS health education gas stations. [6] In addition, schools can appropriately increase sex education courses, recruit full-time teachers, focus on teacher development, and teach students age-appropriate sexual knowledge and basic knowledge of AIDS. For the social aspect, the state should improve the policy on AIDS, and improve the input and use of funds while improving the attention of governments at all levels. Government departments at all levels should give strong support in policy, manpower, financial resources and material resources, and establish special funds for AIDS prevention and control in regional financial work. Second, the publicity should be increased, healthy sexual knowledge and basic knowledge of AIDS should be disseminated, the scope of publicity should be expanded and implemented to everyone. Efforts should be intensified to rectify such high-risk places as chaotic behaviors and drug trafficking, so as to create a safe and harmonious society.

\section{REFERENCES}

[1] Zhu Yanqiu, Liu Wei, Zhang Man, et al. Analysis of monitoring results of hospital environmental sanitation and disinfection and sterilization effect [J]. Guizhou Medicine, 2017, 41 (2): 208-209.
[2] Zhang Fugang, Gao Cunxiang, Chen Tianbo. Discussion on AIDS knowledge education mode in higher hospitals[J]. Journal of Yunnan College of Traditional Chinese Medicine,2010,33(5): 62.

[3] Guo Bingyun, Xie Hanyu. Effect of peer education on improving the awareness rate of AIDS prevention and treatment among college students [J]. Strait Journal of Preventive Medicine, 2010, (6): 90-91.

[4] Guo Bingyun, Xie Hanyu. Effect of peer education on improving the awareness rate of AIDS prevention and treatment among college students [J]. Strait Journal of Preventive Medicine, 2010, (6): 90-91.

[5] Pan Yan, Xu Zhaoqiang, Li Ce, et al. Survey of AIDS kap status among college students [J]. China Public Health, 2012, 28(7): 977979.

[6] Zhang Bifang. Study on AIDS knowledge and attitude intervention measures for college students $[\mathrm{J}]$. Journal of Clinical Medicine and Literature, 2014, 1 (04): 5. 